\title{
REUSABLE TOOL FOR 300MM INTRABAY AMHS MODELING AND SIMULATION
}

\author{
Ahmed El-Nashar \\ Industrial Engineering and Management Systems \\ 4000 Central Florida Blvd. \\ University of Central Florida \\ Orlando, Fl 32816-2993, USA
}

\begin{abstract}
The transition to $300 \mathrm{~mm}$ wafer size introduced a lot of new technologies to wafer fabrication facilities that mandated the presence of intrabay automated material handling systems (AMHS) for moving wafer carriers between the stockers and production tools within a bay. The design of intrabay AMHS depends on the configuration and the mode of delivery. A generic reusable tool is developed for modeling and simulation of the $300 \mathrm{~mm}$ intrabay AMHS different designs. The tool relies on a built-in database and a library containing the different components of intrabay AMHS and the different processing tools. The design of the generic tool guarantees its reusability for building different models of bays with virtually any design. The tool output includes a number of AMHS performance metrics that can be used effectively in comparing different designs of an intrabay AMHS.
\end{abstract}

\section{INTRODUCTION}

Automated material handling system (AMHS) is considered the backbone of semiconductor manufacturing facilities as it is responsible for transporting wafer lots between different bays of a facility, the role of AMHS increased specially after industry transition to $300 \mathrm{~mm}$ wafer size. AMHS consists of material handling equipment and material control system. The material handling system sustains the material flow, while the control system sustains the information flow. In the semiconductor manufacturing industry, the functions performed the AMHS equipment include transport, transfer, and storage of lots; furthermore, the functions performed by the control system include transport control, wafer carrier tracking, and interface to the manufacturing execution system (Bass and Jai 1998). Thus, the AMHS plays a key role in wafer fabrication facilities (fab) and the performance of AMHS directly affects the overall performance of the fab; consequently, it is important to study the effect of different factors that af-

\author{
Khaled S. El-Kilany
}

Industrial and Management Engineering

College of Engineering and Technology

Arab Academy for Science and Technology

Abu Keer, P.O. Box 1029, Alexandria, Egypt. fect the performance of AMHS like configuration, mode of delivery and the number of transport vehicles used.

Furthermore, the complexity of the AMHS and the high costs associated with prototype installation makes it impractical to physically evaluate the performance of such systems under different operating conditions; hence, simulation can be considered a very efficient approach to evaluate the performance of the different AMHS designs. However, it is infeasible to build unique models to simulate all the possible scenarios that need study and analysis. Specially, that these models become inadequate to use after a short period and are often discarded; thus, the amount of time and effort that went into model development becomes worthless (Mukkamala, Smith et al. 2003).

An alternative to unique model creation is to reuse an existing generic model (Mackulak, Lawrence et al. 1998). A component that can be reused multiple times or used in combination with other components can save a great deal of time, money, and human effort. Difficulty of achieving reusability is due to the fact that these components are required to work under a range of possible frameworks (Spiegel, Paul F. Reynolds et al. 2005).

This has lead researchers to develop generic reusable models for wafer fabrication facilities such as the models presented by (Collins, Williams et al. 2005) and (ElKilany, Young et al. 2004).

Right development of generic models allows it to be reused a number of times, which reduces model building time and; ultimately, reduces the total time for the simulation study.

The paper presents a generic reusable tool that is capable of producing different models for bays of a wafer fabrication facility and can configure these models to run seamlessly with different AMHS designs. The next section presents the design of the $300 \mathrm{~mm}$ AMHS used in most fabs today along with a description of the different designs proposed for an intrabay AMHS followed by a description of the developed tool and its built-in database. Afterwards, using the reusable tool for developing a bay model is illustrated. Finally, simulation experiments con- 
ducted on the developed model and their results are revealed.

\section{300MM WAFER FABRICATION FACILITIES AMHS DESIGN}

The AMHS that is used in $300 \mathrm{~mm}$ wafer fabs is mainly composed of interbay and intrabay AMHS that interact together to guarantees delivering the right material to the right place at the right time, and that processing is carried out in the correct sequence of operations.

- The intrabay is used to transfer wafer lots among production tools within each bay using overhead hoist vehicles (OHVs).

- The interbay runs down the centre of the facility to transfer wafer lots between bays.

Stockers placed at the end of the bays are used for lot storage and also serve as a link between the interbay and intrabay systems where lot handling between the two AMHS systems occurs (Shikalgar, Fronckowiak et al. 2002; Kuhl and Christopher 2004).

The common configuration of the interbay/intrabay AMHS in wafer fabs is as shown in Figure 1.

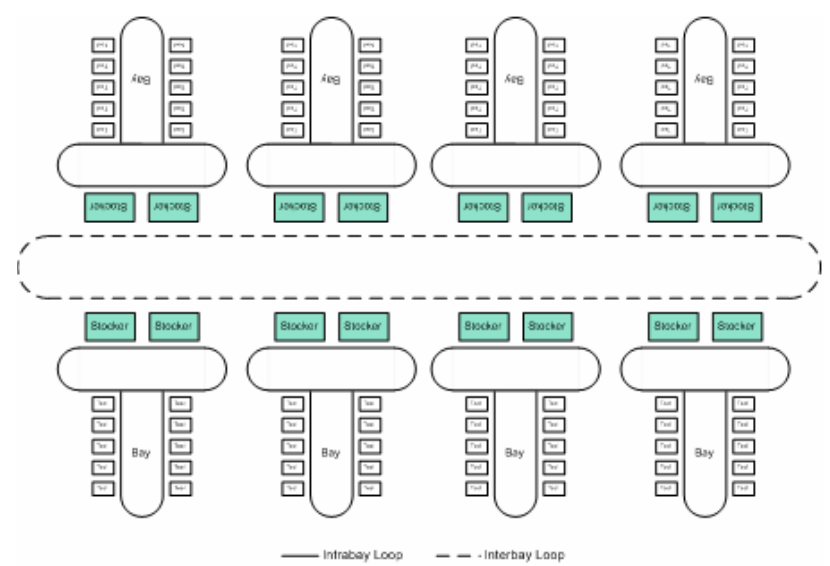

Figure 1: Interbay/Intrabay AMHS configuration in wafer fabrication facilities.

However, this common configuration of the $300 \mathrm{~mm}$ AMHS can be alerted and can be implemented with a variety of approaches, each having different performance characteristics. Specifically, the intrabay AMHS can run with different layout configurations and different modes of lot delivery.

\subsection{Intrabay AMHS Configurations}

The basic AMHS design mentioned in the previous section, specifically lot handling between interbay and intrabay AMHS, can be modified through different configurations of the intrabay AMHS, which can be one of the following:
- Unlinked: in which fab layout consists of interbay that move the wafers between stockers of different bays and a dedicated intrabay AMHS for each bay that moves the wafers between production tools and stockers using a number of OHVs assigned to serve this bay.

- Linked: Merge/Diverge links (MD) can be introduced to the AMHS to link more than one bay together. This provides the automated material handling system the capability to move lots through these links and without the need to the excessive use of the interbay AMHS.

It must be noted that the merge/diverge links are not continuous along the whole bays of the fab; meaning that these links break after a number of bays (two, three, or four) depending on the number of production tools existing in these bays and their production rate.

The main purpose behind using merge/diverge links, is to reduce the required AMHS moves to deliver lots as clearly indicated in Figure 2 (El-Kilany and Young 2004).

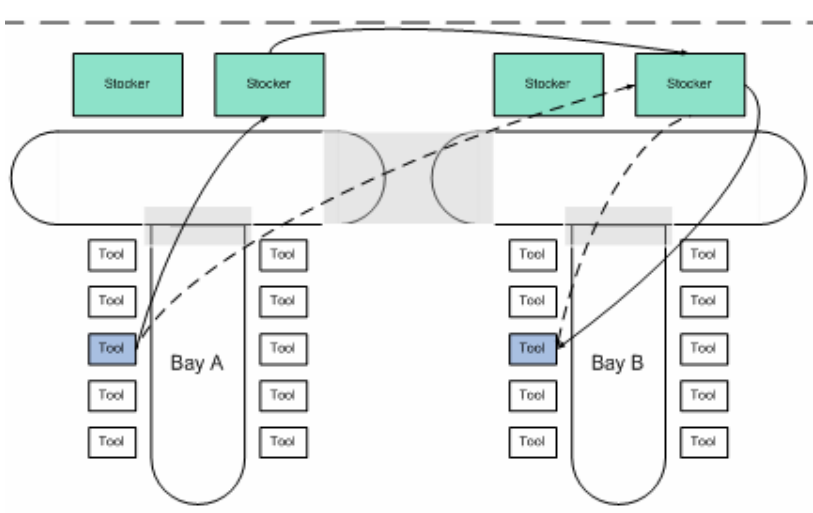

Figure 2: Moving lots between bays with and without a merge/diverge link.

- Without merge/diverge movement of a lot from a production tool in bay (A) to another one in bay (B) is achieved in three moves and with the need to use the interbay AMHS.

- With merge/diverge movement of a FOUP from a production tool in bay (A) to another one in bay (B) is achieved in two moves only and without need to use the interbay AMHS.

\subsection{Lot Delivery Modes}

There are two main types of delivery modes for moving lots in an intrabay AMHS; Stocker-tool-Stocker (STS) and Point-To-Point (PTP).

- Stocker-Tool-Stocker delivery mode means that the lot leaves a stocker and goes to a production tool, and is returned back to a stocker, even if the next operation is carried out by a production tool 


\section{El-Nashar and El-Kilany}

that the OHV passes by. OHV lot delivery using the STS delivery mode is illustrated in Figure 3.

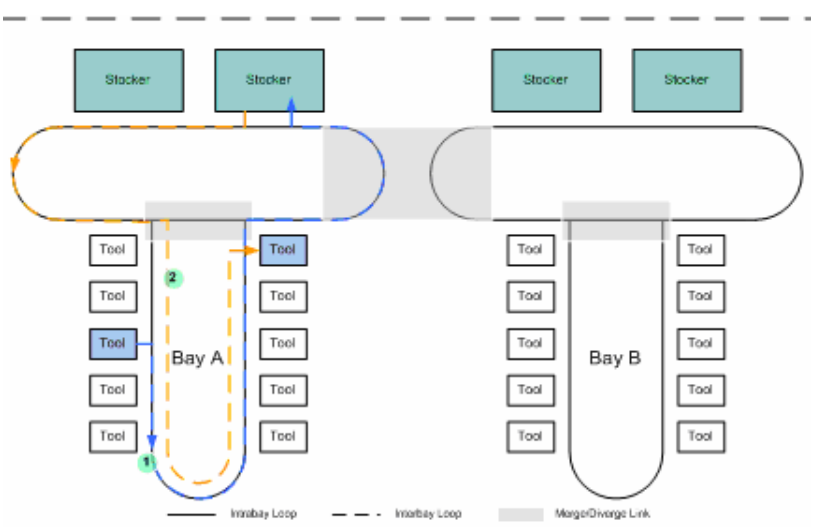

Figure 3: Stocker-Tool-Stocker moves.

- Point-To-Point delivery mode means that a lot can be transferred from a production tool to another one directly, provided that the next process step is carried out by a production tool that the $\mathrm{OHV}$ passes by, or even if this production tool is located in another bay that the OHV can reach through merge/diverge links (given that the intrabay AMHS of these production tools are linked). OHV moves for lot delivery using PTP is illustrated in Figure 4.

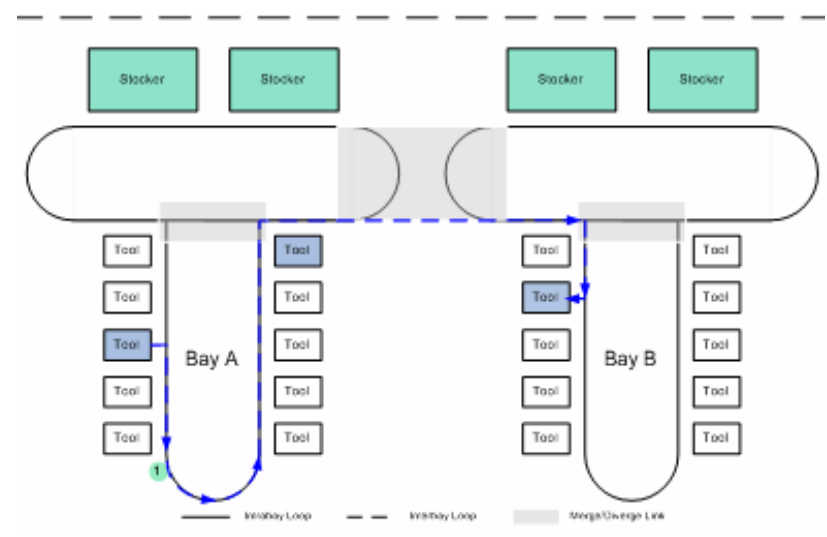

Figure 4: Point-To-Point moves.

\section{GENERIC REUSABLE TOOL}

Component based modelling has been applied to the intrabay AMHS to develop a generic reusable tool that can model and evaluate the performance of the $300 \mathrm{~mm}$ intrabay AMHS under the previously mentioned different operating conditions. This generic tool is composed of a special library that holds a set of building blocks that represent the different components needed to model an intrabay AMHS as shown in Figure 5.

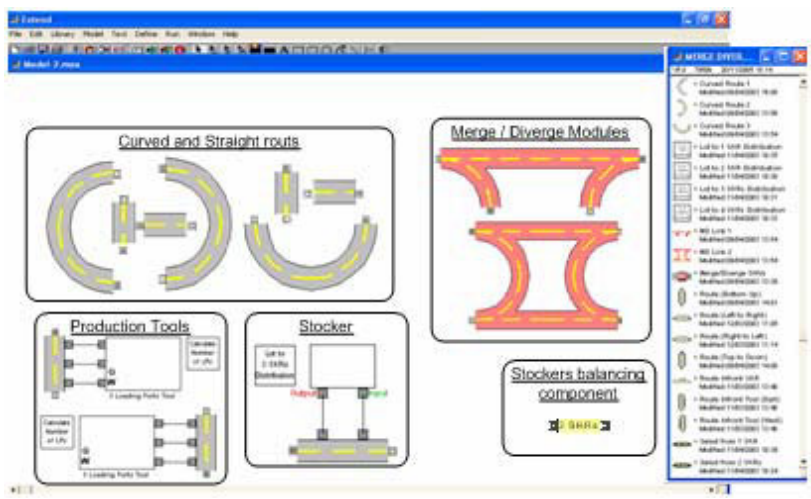

Figure 5: Component included in the tool's library.

The components of this special purpose library were built using the basic blocks of Extend ${ }^{\mathrm{TM}}$ simulation environment. The components that are included in the library represent the different production tools, stockers, Merge/Diverge modules, straight and curved routs, and a component to balance the lots between different stockers within a bay.

The decision variables that can be changed in the models built using this generic reusable tool are:

1. Number of overhead hoisted vehicles (OHVs).

2. AMHS configuration:

- Unlinked (MD-OFF).

- Linked (MD-ON).

3. Mode of delivery:

- $\quad$ Stocker-Tool-Stocker (PTP-OFF).

- Point-To-Point (PTP-ON).

These different settings can be applied to a developed model remotely in a built-in database (discussed further in the next section) without the need to change any of the model's components.

The tool is designed to measure the performance of the modelled system by using the following performance metrics:

- Delivery time.

- Queuing time at the production tool.

- Queuing time at the stocker.

- Moves per hour.

- Bay throughput per hour.

- Production tool utilization.

The $300 \mathrm{~mm}$ intrabay AMHS models that are built using the generic reusable tool are constructed based on a set of assumptions:

- No downtimes for production tools or OHVs.

- OHVs speed is considered uniform; however, two different speeds are defined for straight and curved tracks.

- Processing time on a production tool is constant. However, the processing time for the same pro- 


\section{El-Nashar and El-Kilany}

duction tool changes according to the manufacturing step.

- Interbay AMHS delivery time, lots pickup and drop-off at production tools and at stockers are all factored as uniformly distributed delay time extracted from other simulation models developed by the industry.

- Only one product type is allowed, therefore no prioritisation of lots; however, higher priority is given to lots with higher manufacturing step sequence number and thus is closer towards the end of manufacturing. This helps in pushing lots towards completion and exit of the system.

\section{BUILT-IN DATABASE}

Basically the process of building a model for an AMHS using the presented tool depends on a set of data that can be categorized into five main groups; which are Setup, Bays, Stockers, Process, and production tool sets.

The developed tool has a built-in database that is used to remotely define the different parameters needed to define any component of a bay model. The data needed by such a model are defined in a number of tables within the builtin database. Figure 6 shows the tables of the different data that are defined in the tool's built-in database.

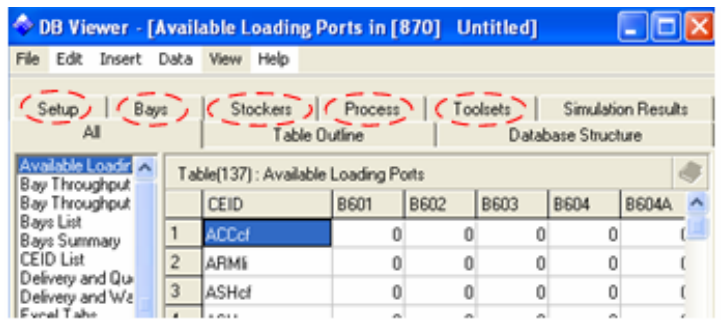

Figure 6: Generic tool database table.

\subsection{Setup Data}

Setup data group is composed of five tables as shown in Figure 7, the data defined in this group act as global parameters responsible for setting up a model.

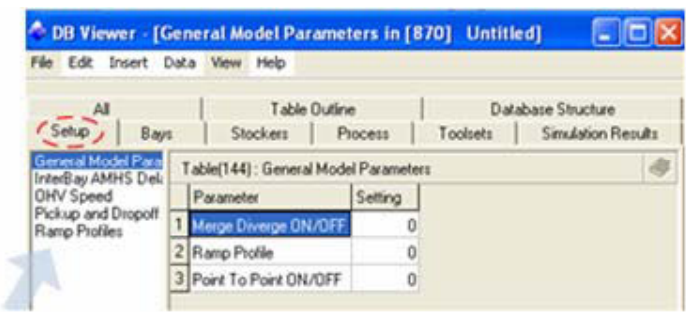

Figure 7: Setup data required to be introduced to the model.
These tables are defined as follows:

- General model parameters: defines the configuration of the AMHS used (MD - ON/OFF), the delivery mode (PTP - ON/OFF), and the ramp profile to be used. Switching the MD and PTP ON/OFF is simply by defining $0 / 1$ values in the setting field.

- Interbay AMHS delay: defines the time of lot transfer using interbay AMHS, which is a randomly generated value based on a uniform distribution.

- OHV Speed: defines the speeds of OHVs on straight and curved routes as constant values provided by the OHV supplier.

- Pickup and Drop-off time: the data of lot dropping off time at the production tool/stocker and lot picking up time from the production tool/stocker are defined in this table. These are represented by a uniform distribution and are provided by the OHV supplier.

- Ramp profile: defines the number of wafers start per week (WSPW) introduced to the fab each week.

\subsection{Bays Data}

Bays data is divided into two main tables, as shown in Figure 8, where the following data is introduced:

- Bays summary: this table includes data about each bay like the number of OHVs assigned to that bay, the name of the stockers that are assigned to serve it, and the preferred stocker for lot pickup/drop-off.

- Bays list: this table is a one field table that lists all bays that exist in the wafer fabrication facility.

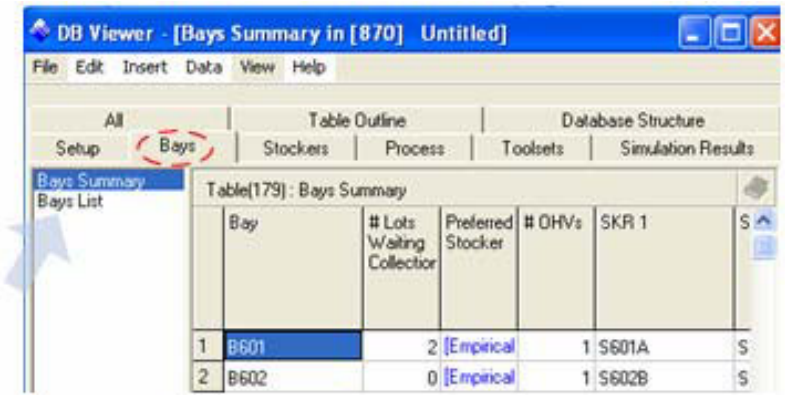

Figure 8: Data tables regarding the different bays.

\subsection{Stockers Data}

Figure 9 shows the two tables in the stockers' data group, which are: 
- Stockers: defines the capacity of each stocker in the fab, the number of lots ready for pickup by an OHV, and the total number of lots in stock.

- Stockers list: this table lists all stockers in a fab.

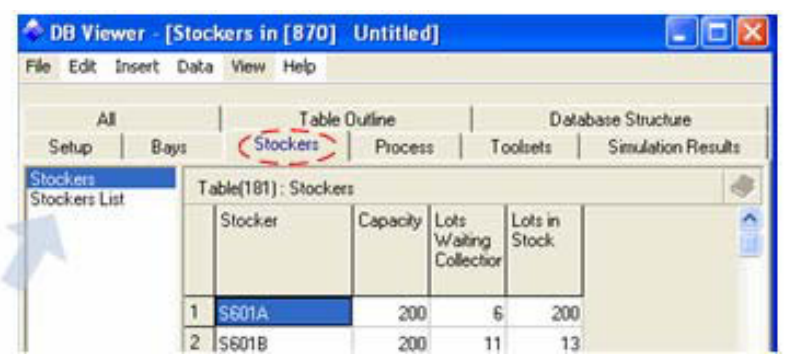

Figure 9: Data tables concerning the different stockers.

\subsection{Process Data}

Process data is divided into two main tables, as shown in Figure 10 which include the following data:

- Process flow: this includes a list of all processing steps required to complete the processing of a wafer. For each step the following is defined: the functional area, the step name, the production tool required to perform that step, the bay name where the production tool needed for this processing step is located, and the processing time needed to carryout each step.

- Ramp profile: defines the WSPW introduced to the fab each week.

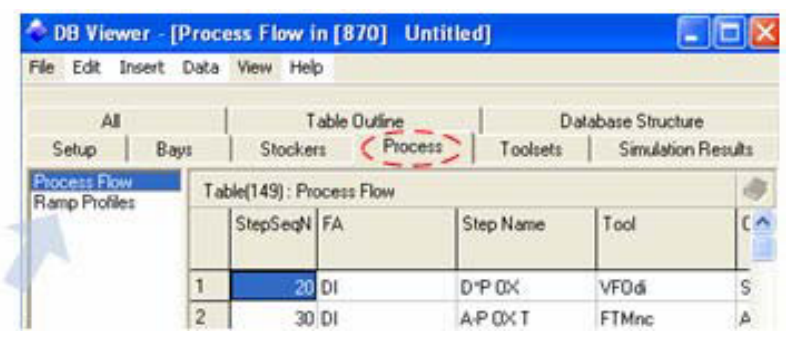

Figure 10: Process data tables.

\subsection{Production tools Data}

The data regarding the different production tools in the wafer fabrication facilities is divided into two tables, as shown in Figure 11 which are:

- Production tool list: this table lists all production tools in the fab, this table is titled by tool ID list in the presented tool.

- Production tool data: defines the number of loading ports of each production tool, this table is titled by toolset data in the presented tool.

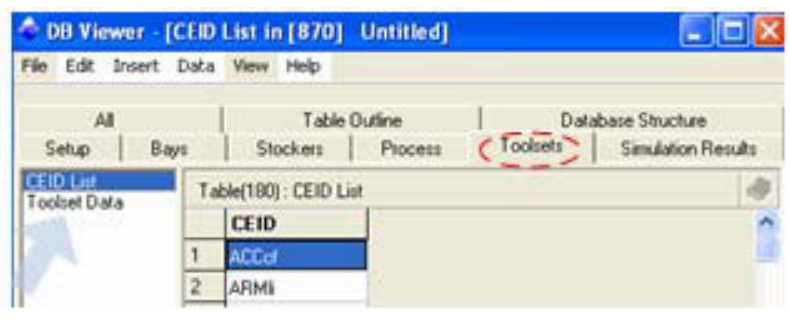

Figure 11: Data tables for production tools.

\section{BUILDING A MODEL USING THE TOOL}

After defining all the required data in the built-in database, the components of the special purpose library (shown in Figure 5) can be dragged from the menu and configured as needed to build the required model.

Building a single bay can be divided into three main steps, which are adding and configuring:

1. Stockers.

2. Production tools.

3. Routes that link stockers and production tools. Addition of the components is simple a drag-and-drop task of the components needed to model a bay; whereas configuration of the component depends on its type and is discussed briefly in the following sections.

\section{$5.1 \quad$ Stockers}

Drag the block representing the stocker from the library, and configure it according to its position in the system. The configuration of this component is carried out at eight different points as shown in Figure 12.

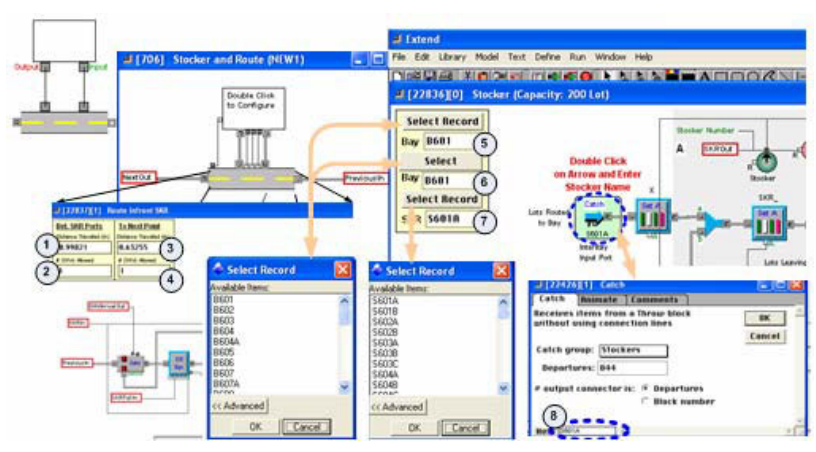

Figure 12: Stocker configuration.

Description of data that should be introduced to stocker block is shown in Table 1; the table summarizes all the data required to configuring stocker block. 
Table 1: Required data to configure stocker block.

\begin{tabular}{rll}
\hline Point & Definition & Required Action \\
\hline 1 & $\begin{array}{l}\text { Distance between loading } \\
\text { ports }\end{array}$ & $\begin{array}{l}\text { Enter value in } \\
\text { meters }\end{array}$ \\
2 & $\begin{array}{l}\text { OHVs allowed between } \\
\text { loading ports }\end{array}$ & $\begin{array}{l}\text { Enter number of } \\
\text { OHVs }\end{array}$ \\
3 & $\begin{array}{l}\text { Distance between stocker } \\
\text { output and next point }\end{array}$ & $\begin{array}{l}\text { Enter value in } \\
\text { meters }\end{array}$ \\
4 & $\begin{array}{l}\text { OHVs allowed between } \\
\text { stocker output and next point }\end{array}$ & $\begin{array}{l}\text { Enter number of } \\
\text { OHVs } \\
\text { Select bay from } \\
\text { drop-menu } \\
\text { Determine } \\
\text { stocker number }\end{array}$ \\
& Stocker location & \\
7,8 & Stocker number & \\
& &
\end{tabular}

\subsection{Production Tools}

The next step in building the model is adding the production tools, in this steps the block of the production tool should be dragged from the menu and configured every time a production tool is required to be added to the model. The configuration of this block should be carried out at nine different points as shown in Figure 13.

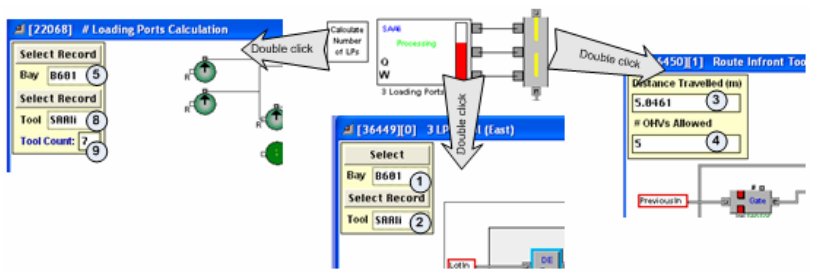

Figure 13: Production tool configuration.

The data that should be configured in the production tool block are summarized in Table 2 .

Table 2: Required data to configure production tool block.

\begin{tabular}{|c|c|c|}
\hline Point & Definition & Required Action \\
\hline 1,5 & Bay where the block exists & $\begin{array}{l}\text { Select bay from } \\
\text { drop-menu }\end{array}$ \\
\hline 2,8 & Production tool name & $\begin{array}{l}\text { Select tool from } \\
\text { drop-menu }\end{array}$ \\
\hline 3 & $\begin{array}{l}\text { Distance between the produc- } \\
\text { tion tool and the next one. }\end{array}$ & $\begin{array}{l}\text { Enter distance } \\
\text { in meter }\end{array}$ \\
\hline 4 & $\begin{array}{l}\text { OHVs allowed in this dis- } \\
\text { tance }\end{array}$ & $\begin{array}{l}\text { Enter number of } \\
\text { OHVs }\end{array}$ \\
\hline 9 & $\begin{array}{l}\text { Number of production tools } \\
\text { from the same type }\end{array}$ & $\begin{array}{l}\text { Enter number of } \\
\text { tools in the by }\end{array}$ \\
\hline
\end{tabular}

\subsection{Routes}

The last step in building the model is adding the blocks that represent different routes, and configure them according to the bay being modeled.
There are three main types of routes that are defined to connect the production tools and stockers, which are:

- Curved and straight routes.

- Merge/diverge links type 1 (MD1).

- $\quad$ Merge/diverge links type 2 (MD2).

\subsubsection{Curved and Straight Routes}

The configuration of the curved or straight routes is carried out at two points as shown in Figure 15.

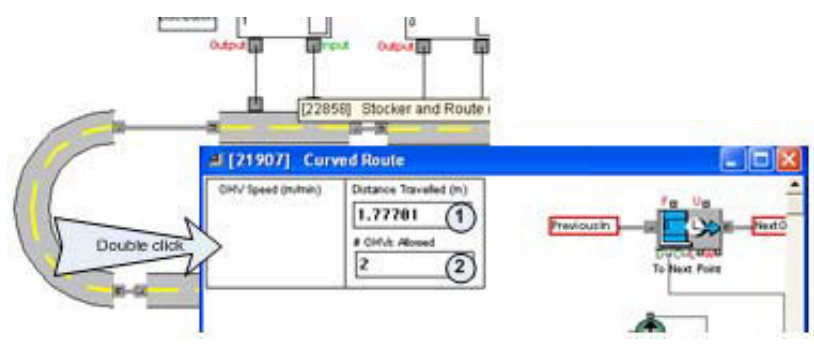

Figure 14: Route block configuration.

That data that are required to be configured in the block of straight/curved routes are summarized in Table 3.

Table 3: Required data to configure route block.

\begin{tabular}{rll}
\hline Point & Definition & Required Action \\
\hline 1 & Distance traveled by vehicle & $\begin{array}{l}\text { Enter value in } \\
\text { meters }\end{array}$ \\
2 & $\begin{array}{l}\text { OHVs allowed in this dis- } \\
\text { tance }\end{array}$ & $\begin{array}{l}\text { Enter number of } \\
\text { OHVs }\end{array}$ \\
\hline
\end{tabular}

\subsubsection{Merge/Diverge Links Type 1 (MD1)}

To allow the vehicles to choose between moving in bay's outer loop and entering the bay to unload or pick up load, Merge/Diverge module (MD1) can be added to the model. This component can be added by dragging the block of Merge/Diverge module (MD1) form library, this block is configured at ten different points as shown in Figure 15.

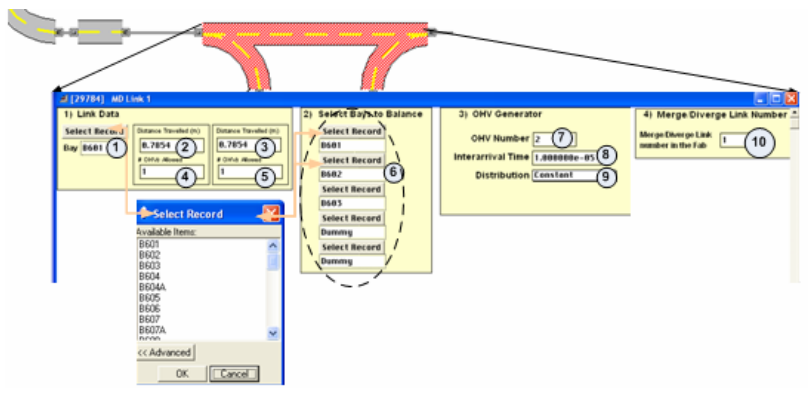

Figure 15: Merge/Diverge Module (MD1). 
The data that should be configured for this component are summarized in Table 4.

Table 4: Required data to configure MD1 link block.

\begin{tabular}{|c|c|c|}
\hline Point & Definition & Required Action \\
\hline 1 & Bay where the block exists & $\begin{array}{l}\text { Select bay from } \\
\text { drop-menu }\end{array}$ \\
\hline 2,3 & $\begin{array}{l}\text { Distance of curved loop of } \\
\text { MD1 }\end{array}$ & $\begin{array}{l}\text { Enter distance } \\
\text { in meter }\end{array}$ \\
\hline 4,5 & $\begin{array}{l}\text { OHVs allowed in curved } \\
\text { loop of MD1 }\end{array}$ & $\begin{array}{l}\text { Enter number of } \\
\text { OHVs }\end{array}$ \\
\hline 6 & Bays that are linked together & $\begin{array}{l}\text { Select bays } \\
\text { from drop-menu }\end{array}$ \\
\hline 7 & Number of generated OHVs & $\begin{array}{l}\text { Enter number of } \\
\text { OHVs }\end{array}$ \\
\hline 8 & $\begin{array}{l}\text { Inter-arrivals between gen- } \\
\text { erated OHVs }\end{array}$ & $\begin{array}{l}\text { Enter inter- } \\
\text { arrival time }\end{array}$ \\
\hline 9 & $\begin{array}{l}\text { Select distribution of inter- } \\
\text { arrival time }\end{array}$ & $\begin{array}{l}\text { Select distribu- } \\
\text { tion from drop- } \\
\text { menu }\end{array}$ \\
\hline 10 & $\begin{array}{l}\text { Determine the link that is } \\
\text { being modeled }\end{array}$ & $\begin{array}{l}\text { Enter the num- } \\
\text { ber of the link }\end{array}$ \\
\hline
\end{tabular}

\subsubsection{Merge/Diverge Links Type 2 (MD2)}

To link different bays together Merge/Diverge module (MD2) is used, this module allows the vehicles to decide whether to stay in the same bay or to pass to another one according to the existing conditions.

The configuration of this block should be done at only two points as shown in Figure 16, in which the user define the bays that are connected by this module.

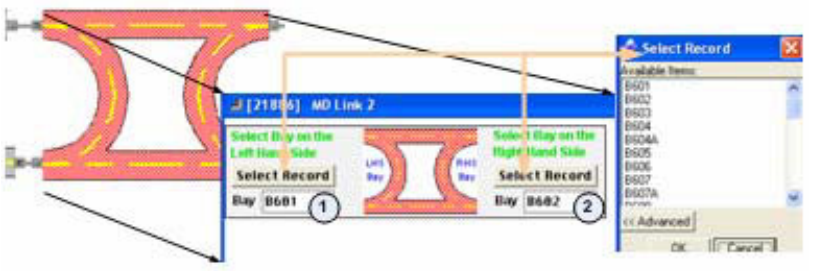

Figure 16: Merge/Diverge module (MD2) configuration.

After defining the different routed needed to link the stockers and the production tools, the model becomes ready to run and providing the user with all results regarding the performance of the intrabay AMHS.

The reusability nature of the presented tool allows the user to easily change the operating conditions and re-run the model again to investigate the effect of these changes on the performance of the intrabay AMHS.

\section{SIMULATION EXPERIMENTS AND RESULTS}

\subsection{Model Brief Description}

A model consisting of three bays, as shown in Figure 17, has been used to perform a number of planned simulation experiments. Each bay has different number of different types of tools and a number of stockers.

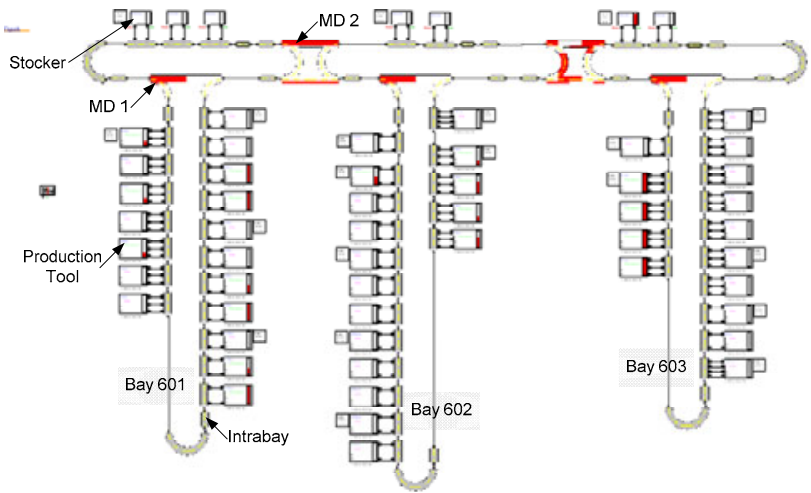

Figure 17: The model used to perform the simulation experiments.

All the three bays are linked together with Merge/Diverge modules (MD 2) that allow the free movement of vehicles (OHVs) among the different bays, also another Merge/Diverge module (MD 1) installed in each bay that allow vehicles to enter the bay or not depending on the prevailing requirements.

\subsection{Experimentation with the Developed Model}

\subsubsection{AMHS Operating Conditions}

The system under study can be described in terms of two main features: configuration and mode of delivery. The configuration of the system is represented by the state of Merge/Diverge (MD), while the mode of delivery is represented by the state of Point-To-Point (PTP). Combining these two features produces four alternative operating scenarios as shown in Table 5.

Table 5: AMHS different operating scenarios.

\begin{tabular}{ccc}
\hline Operating & \multicolumn{2}{c}{ Features } \\
\cline { 2 - 3 } Scenarios & Merge/Diverge & Point-to-Point \\
\hline Scenario 1 & OFF & OFF \\
Scenario 2 & OFF & ON \\
Scenario 3 & ON & OFF \\
Scenario 4 & ON & ON \\
\hline
\end{tabular}

It must be noted that the no changes are needed to be introduced to the developed model to execute these sce- 


\section{El-Nashar and El-Kilany}

narios, as switching from one scenario to another or even running the model with different number of OHVs is defined remotely in the built-in database.

\subsubsection{Motivation of Conducting the Experiments}

Because of high cost of Overhead Hoisted Vehicles (OHVs), semiconductor manufacturers are aiming at minimizing the number of OHVs needed to attain the target delivery time. This goal is mainly achieved through revising the designs of automated material handling system (AMHS). Therefore, the main purpose of conducting such simulation experiments is to determine the optimum number of OHVs needed to achieve a target delivery time under the different operating conditions.

\subsubsection{Performance Measures}

A number of performance measures are used to evaluate the performance of the automated material handling systems (AMHS). The main parameter is usually taken as the delivery time, beside other measures such as queuing time at tools, queuing time at stocker, and moves per hours are used. These different measures are defined as follows:

1. Delivery Time: The time spent by a lot (unit product) to be transferred from a current port to the next loading port. The time begins at the request for carrier movement and ends when the carrier arrives at the destined load port of the receiving equipment, as mentioned in the international technology roadmap for semiconductors (ITRS 2004). The delivery time is composed of a waiting time of the lot at tool or stocker, picking up time, transporting time of the lot to the next point, and finally dropping off time of the lot at the tool. The peak delivery time is prescribed in the ITRS by a value of 12 minutes. More restricted delivery time standard of the value of 8 minutes is stated by one of the greatest semiconductors manufacturing companies.

2. Queuing Time at Tool: It is the time spent by a lot at the tool waiting for an $\mathrm{OHV}$ to be transferred to its next destination.

3. Queuing Time at Stocker: It is the time spent by a lot at the stocker waiting for an OHV to be transferred to its next destination.

4. Total Moves per Hour: It is the total number of moves done by OHVs per hour to transfer lots from tools to the stockers or vice versa.

\subsubsection{Performance Measures Estimation}

The model calculates the mean and standard deviation for delivery time, and queuing time at tool. The 3-sigma peak values of these previous parameters are used to represent the highest time values that could occur.
The model accumulates the moves and bay throughput that occur every hour in each bay. These accumulated values are processed to calculate the average and standard deviation of these parameters, and then the 2-sigma peak values are calculated to estimate the highest moves or bay throughput per hour that can be achieved.

Finally, tool utilization is calculated by collecting the utilization of each tool reported by the model and then the average and standard deviation of the whole system are calculated.

\subsection{Comparing System Performance}

Figure 18 shows a comparison between the different system performances under the different operating conditions, using the first scenario (MD-OFF/PTP-OFF) as a reference for comparison. Positive percentage values means improved performance and negative percentage values means worse performance.

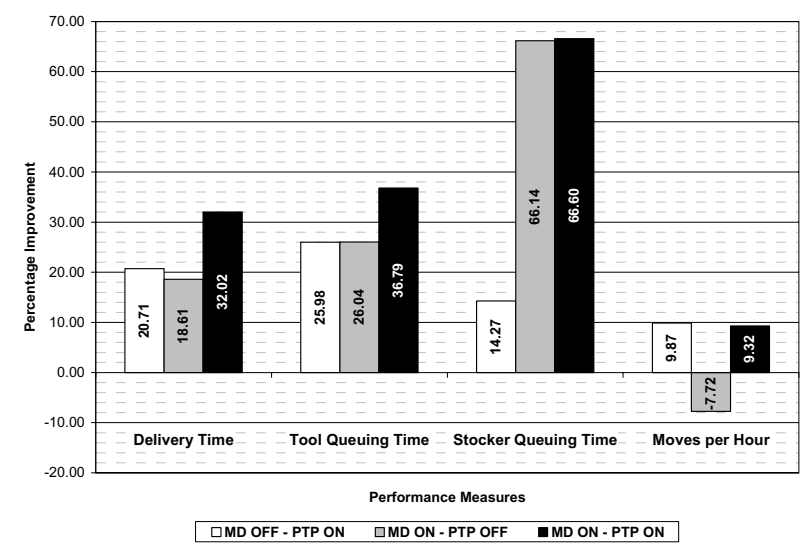

Figure 18: Comparing system performance under different conditions.

The figure shows that by implementing point-to-point mode of delivery without using merge/diverge capability (scenario 2); delivery time is improved (reduced) by about $20 \%$. Such enhancement is derived from reducing waiting time at the tool by $26 \%$ and waiting time at the stocker by $14 \%$.

While in case of using merge/diverge capability without implementing point-to-point delivery mode (scenario 3 ); delivery time is enhanced by $18 \%$. This is derived from reducing waiting time at the tool by $26 \%$ and waiting time at stocker by $66 \%$.

By reviewing the results of scenarios 2 and 3 , it shows that even though the reduction in waiting time at stockers is greater in scenario 3 and the reduction in the waiting time is almost the same in both cases, the reduction in delivery time in the scenario 2 is higher than that of the scenario 3 . 
This can be interpreted by reviewing the moves per hour (MPH) in both scenarios. MPH results shows that in scenario 3 the moves per hour increased by about $8 \%$, which diminished the effect of great reduction in waiting time at the stocker; achieved by using merge/diverge capability (PTP requires a lesser number of moves). This clarifies why the reduction in delivery time in the scenario 3 is lower than that of the scenario 2 .

The system reaches its best performance by using merge/diverge capability combined with implementing point to point mode of delivery (scenario 4 ). In this condition the delivery time is reduced by $32 \%$, which is derived from reducing waiting time at the tool by $36 \%$ and waiting time at the stocker by $66 \%$.

This brief description of the simulation experiments shows that the presented tool can provide the user with a variety of outputs that can help in analyzing the performance of the system under investigation, or in comparing the performance of the different proposed designs.

\section{CONCLUSION}

Automated material handling systems play a very important role in wafer fabrication facilities, the new technologies introduced to wafers fabrication facilities mandated the presence of intrabay AMHS. The design of intrabay AMHS has a direct effect on its performance, which in turn affects the whole performance of the fab; in addition, the cost of intrabay AMHS is very high, which necessitate the use of modeling and simulation to investigate the performance of the intrabay AMHS under the possible different operating conditions prior to implementation. A reusable tool has been developed, which demonstrates the efficiency and effectiveness that can be gained from such a tool in modeling and simulation of different proposed designs of an intrabay AMHS.

\section{REFERENCES}

Bass, E. and P. Jai (1998). Metrics for 300mm Automated Material Handling Systems (AMHS) and Production Equipment Interfaces: Revision 1.0, International SEMATECH.

Collins, D. W., K. Williams, et al. (2005). Getting Ready for the Simulation Revolution in 300mm Fab Productivity! IEEE International Symposium on Semiconductor Manufacturing, 2005. ISSM 2005.

El-Kilany, K. S. and P. Young (2004). Process Design of Semiconductor Intrabay Amhs Using Simulation. 14th International CIRP Design Seminar 2004, Cairo, Egypt.

El-Kilany, K. S., P. Young, et al. (2004). "Generic tool for modelling and simulation of semiconductor intrabay material handling system." Journal of Materials Processing Technology 155-156: 1927-1934.
ITRS. (2004). "Factory Integration." Retrieved 2/4/2007, from

http://www.itrs.net/Links/2004Update/2004_09_Fact ory.pdf.

Kuhl, M. E. and J. Christopher (2004). Capacity Analysis of Automated Material Handling Systems in Semiconductor Fabs. Proceedings of the 2004 Winter Simulation Conference.

Mackulak, G. T., F. P. Lawrence, et al. (1998). Effective Simulation Model Reuse: A Case Study for Amhs Modeling. Proceedings of the 1998 Winter Simulation Conference, Washington, DC.

Mukkamala, P. S., J. S. Smith, et al. (2003). Designing Reusable Simulation Models for Electronics Manufacturing. Proceedings of the 2003 Winter Simulation Conference.

Shikalgar, S. T., D. Fronckowiak, et al. (2002). 300mm Wafer Fabrication Line Simulation Model. Proceedings of the 2002 Winter Simulation Conference.

Spiegel, M., J. Paul F. Reynolds, et al. (2005). A Case Study of Model Context for Simulation Composability and Reusability. Proceedings of the 2005 Winter Simulation Conference.

\section{AUTHOR BIOGRAPHY}

AHMED EL-NASHAR is a Ph.D. student in the Department of Industrial Engineering and Management Systems at the University of Central Florida. He has previously held the position of teaching assistant in the department of industrial and management engineering at college of engineering and technology, Arab academy for science and technology. His research interest lies in the area of stochastic discrete-event systems simulation. <elnashar77@gmail.com>.

KHALED S. EL-KILANY is an assistant professor in the Industrial and Management Engineering Department at College of Engineering and Technology, Arab Academy for Science and Technology. He has previously held the position of interim chairman of the department for two years. His research interest lies in the analysis and improvement of manufacturing systems performance using discrete-event systems simulation and artificial intelligence. Currently, his areas of research application include supply chain management, production planning, project scheduling, and process design. He has received his Ph.D. in Mechanical and Manufacturing Engineering form Dublin City University, Ireland; where his research work included modeling and simulation of automated material handling system of Intel's latest wafer fabrication facilities.<kkilany@aast.edu>. 